\title{
OB-scene, a Live Audio/Visual Performance for Photoplethysmograph and Female Body
}

\author{
ANNA TROISI \\ EMERGE, Experimental Media Research Centre, Bournemouth University, Weymouth House W211, Talbot Campus, Fern Barrow, \\ Poole, BH12 5BB, UK \\ Email: atroisi@bournemouth.ac.uk
}

$O B$-scene is a performance centred on a live sonification of biological data gathered in real-time with a medical vaginal probe (photoplethysmograph), made by the author. The use of the photoplethysmograph, which takes inspiration from the first medical vaginal probes used for diagnostic purposes by Masters and Johnson (1966) introduces a media-

archaeological aspect to this work. Data gathered through the probe is processed and transformed into sound and visuals projected in the exhibition space. $O B$-scene takes inspiration from Jane Bennett's Vibrant Matter (2010) in which she argues that human agency has echoes in non-human nature and vice versa, shifting away from anthropocentrism towards the concept of 'vital materiality' that runs across bodies, both humans and unhuman. Furthermore, $\mathrm{OB}$-scene is affiliated with an emerging movement of women and technology called 'XenoFeminism' (XF). It introduces the idea of technoalienation and focuses on the concept of other/diverse desires, new forms of desiring, experiencing something other (Laboria Cuboniks 2015). In this specific work, this takes the form of a technofeminism incorporating the fluid, the non-human and the diverse. In this performance, the body is fused with the technology, rather than empowered or enhanced by technology itself, body and technology become a unique actant (Latour 2009) enabling the audience to experience the sensorial assemblage as a space for communal experience with political implications. $\mathrm{OB}$-scene is as an immersive environmental work where the senses, affect and memory were key features of 'assemblage thinking' (Hamilakis 2017).

\section{THE PERFORMANCE}

$O B$-scene represents an explicit artistic act of remediation. The performance consists of a live sonification of biological data gathered in real time through a customised vaginal probe (photoplethysmograph).

This work is conceived for an audience of 30 participants in a small room, such as a changing room or a wider space like a dance studio. The performer occupies one side of the room, back to the wall, legs crossed. A laptop sits to the side, linked to the performer by cables that transfer data from the medical probe to the software, which is running on the computer (Figure 1). The audience is invited to enter the room and sit as soon as the performance starts (not before). In this way, the audience can grasp the scene upon entering, and individuals can find their own

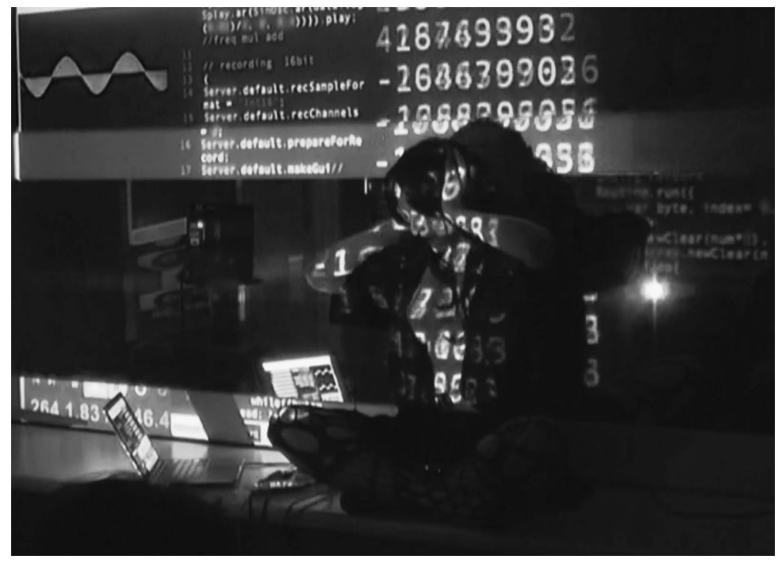

Figure 1. OB-scene performed at the Metabody Forum, 4-9 April 2016, Brunel University.

comfortable distance from the focus of the performance. In past iterations, this moment of introduction and settling in only lasted a few seconds.

Mirrors are used as projection surfaces to avoid the use of multiple projectors in the room which would multiply the level of unwanted noise. The room is kept very dark so the mirrors can function both as projection surface and as reflection surface for the visual.

The idea of the projection is derived from the practice of live-coding with Supercollider, in which musicians have moved from graphical programming interfaces to command-line control of audio, projecting their coding on screen.

Many artists $^{1}$ are used to projecting their laptop screens to give the audience a clearer idea of the various processes involved in generating their sounds. $O B$-scene does not imply a live coding practice; instead, it represents the use of code and the generation of live data. Therefore, the laptop screen is projected and made visible to the audience, composed of three sections (three windows kept on the screen): the streaming numerical data from the sensor; the code in

${ }^{1}$ Slub, A. McLean and A.Ward, a London-based duo (Burland and McLean 2016); Alexandra Cárdenas, a Colombian composer and improviser now based in Berlin (Cargocollective.com 2018); Marije Baalman, artist and researcher and developer based in Amsterdam (Marijebaalman.eu 2018). 
the Supercollider window, which is static and launched by the performer at the start of the piece; and a live data visualisation of the sinusoidal sound wave generated by the probe.

The probe created for OB-scene is a photoplethysmograph (VPP). In medicine, it has for decades served as the main measuring device to assess female sexual dysfunction (Heiman 1977; Laan, Everaerd, Velde and Geer 1995). The use of the photoplethysmograph, which takes inspiration from the first medical vaginal probes used for diagnostic purposes by Masters and Johnson (1966) and further developed by Geer, Morokoff and Greenwood (1974), introduces a media-archaeological aspect to this work which will be made more explicit later in this article.

This device enabled researchers to focus specifically on sexual arousal in women. In fact, other physiological measures are not able to differentiate sexual arousal from other forms of autonomic arousal (Zuckerman 1971). The probe operates on the principle that vasocongestion occurs within the vagina as arousal take place (Masters and Johnson 1966). The probe is constituted by two main components: a light emitter (infrared diode) directed at the wall of the vagina and a photodetector that detects the backscattered incident light. As vasocongestion occurs, less light is reflected from the tissue, and the output of the photodetector changes to indicate the change (Beck, Sakheim and Barlow 1983).

The signal AC (Alternating Capacitive Coupling) is used to generate live data for the performance. The probe produces a signal, which can be used to understand two different parameters. The probe can work, in fact, as vaginal pulse amplitude (VPA) or vaginal pressure pulse (VPP) indicator. For this work, the VPP indicator is used.

The interface between the medical probe and the software (Supercollider) is an Arduino Duemilanove, a well-known microcontroller board used to receive and transmit serial data.

Data is processed and transformed, through original software coded in Supercollider, into sound and raw data projected as previously explained in the exhibition space. The sensor probe, software, and the audio composition were all made by the author.

The sound composition is stereo, combining two layers: a composed layer and a live data sonification. The purely composed layer consists of patterns of sounds. In Supercollider the author used two different instances of glitching sounds which play independently between speakers. The glitch sound is an enveloped pink noise which was filter with a high RQ. ${ }^{2}$ The decay time of the noise envelope was modulated with a

\footnotetext{
${ }^{2}$ The return quotient (RQ) affects the slope of the source spectrum, a large RQ corresponds to greater attenuation of the higher frequencies.
}

LFNoise1 which is a stochastic noise generator (linearly interpolated random values). Bass sounds were tuned through two sine oscillators triggered by an impulse generator to widen the spectrum of the composition.

Artists who have inspired this layer of the composition are Alva Noto and Ryuichi Sakamoto who have collaborated over the last 15 years, experimenting with the use of clipped samples in a minimalistic context. Also, the work of Ryoji Ikeda is relevant here, for his experiments with sine tones and noise using high frequencies framed into beat patterns.

The second layer is a direct mapping of the probe signals into a sinusoidal sound (sonification) which persists for the entire duration of the performance and change frequency due to the transformation of the signal (pulse rate accelerates). The effect is a pulsing drone with a slow increase in pulse frequency over time.

The performer is wearing headphones and remains seated for the duration of the piece. The audio played on the headphone is not audible by the audience, serving only as 'secret audio' or 'secret track', as some audience members referred to it after experiencing the performance. The role of the 'secret' audio is to prompt sexual arousal, which produces changes in the data gathered by the vaginal probe.

The audio consists of a short story written for $O B$-scene and read by an anonymous author. The timeline of the teasing audio was designed to intersect with the sound performance in ways that the audience only experiences second-hand. ${ }^{3}$

The aesthetic choice of minimalism and adoption of electronic purely synthetic sounds as well as sounds generated by analogue signals is tied to the philosophical vision of this work. The author attempts a 'sentic' approach in which the emotional response is considered as input to the machine (see further below). Artistic communication during the performance is not mediated by gestures and the presence of the performer is reduced to have minimal impact in term of movements on stage.

The mixture of synthetic sounds and analoguegenerated sounds are thought to enhance the perception of integration between the apparently inert technology

\footnotetext{
${ }^{3}$ The 'teasing audio' is used for its potential in term of response. Sexual arousal can be elicited by exposure to internal or external sources of sexual stimuli. In a study conducted by Heiman (1980) within a research in the context of sexual psychophysiology it is evidenced that women show a more reliable response in term of sexual arousal to audiotaped descriptions of sexual interactions or sexual fantasy (internal source) than audiovisual depictions of sexual activity. More recent studies (Chivers, Seto, Lalumière, Laan and Grimbos 2010) confirmed instead that female arousal is subject to the feeling of sexual arousal for women and sometimes can be disconnected from the physiological reaction. While this article does not aim to confirm or dismantle any theory, it uses the 'audiotape' stimulus in an experimental form for artistic purpose, relying on the fact that this worked for the performer and remains discrete and at the same time mysterious for the audience.
} 
and the human body with its emotional and physiological changes.

\section{THE ACTANT PERFORMER}

Recent work by the author consists of digital bodyperformances, digital audio/video installations, acousmatic compositions and digital environments. Under the broad heading 'sensing data', all these projects seek to connect the multiple sensory registers in which we can think about the 'ecology of things' (Bennett 2010): the relationships between humans and the environment can be conceived on scales ranging from the intimate to the global. Data, when treated as artistic 'raw material', can provide evidence of bodies (and communities) adapting through culture and technology to a changing natural and post-industrial environment.

$O B$-scene is a performance aiming to stage an environment where audience and performer share a very individual and intimate erotic experience in the same space and soundscape. While the words 'sensing data' are used to refer to sensors or systems enabling data-gathering and possibly transforming it into something else, in this work the author intentionally gives less importance to the mechanisms, and considers data as something that can be apprehended by the senses.

In OB-scene, data and machines represent the actant, in the sense of Latour's 'Third meaning of technical mediation' which he describes using the example of a broken overhead projector: it is only when the attention of the audience moves towards the broken silent object that it really becomes the actant. All human gestures around the machine are moved by the object itself which needs to be repaired in order to turn back into a black-box, newly inorganic, unhuman and inert while showing its functionality and serving the humans (Latour 2009).

The intent is to flip the common way we look at data as a 'cold', 'unhuman', 'inorganic' or 'inert' matter, while at the same time worthy of being understood, visualised or explained. $O B$-scene abolishes the 'partition of the sensible', to use Jacques Rancière's expression, which defines the forms of part-taking by defining the modes of perception in which they are inscribed (Rancière, Panagia and Bowlby 2001). The partition of the sensible constitutes for Rancière a tool to address the reconfiguration of the relationship between politics and aesthetics. In $O B$-scene, a similar reconfiguration takes place: intentionally, the author does not separate the gesture of the performer from the data produced by the performer. Any gesture and movement if coupled or defined as a part would minimise the agency of the data itself when simply mapped into a sound experience.

With these premises, the involvement of sensors and gestures in the performance is of secondary importance, while the environment and physical response (for both humans and machines) are the main focus. Data and machines do not represent the tools for the body to perform but they perform alongside the human performer. $O B$-scene is an attempt to elide what we commonly take as distinctive about humans, considering instead the combination of a human body with inert technology as a completely new system, the actual actant performer, the cybernetic organism (cyborg).

The adoption of the cyborg as actant-performer shifts the conceptual focus away from considering $O B$-scene as a mere performance which utilises new media technology, instead resonating with the more inclusive theory of Wiener who defined cybernetics as 'communication and control' together (Wiener 1988).

The 'artist as cyborg' can refer not only to the materiality of the forms used to create art (i.e. machines and/or new media technology) but also to an aesthetic which is modelled on the core principles of cybernetics. (Tenney 2010)

In Wiener's theory, as well as in the work presented in this article, the idea of the cyborg has implications which touch on communication theory at the level of messages sent and received in between parties, system theory (the whole body/system which act as transmitter and receiver) and control theory which is related to the effect that those messages produce in the system (Wiener 2007). For the purposes of this article, the focus is on the cyborg as both image and concept (Biro 2009). Biro's assertion resonates with the idea of cyborgs as 'simultaneously entities and metaphor, living being and narrative constructions' (Hayles 1999: 114). $O B$-scene is intended as a performance of an assemblage of parts (human and unhuman) where the image (entity) and the concept (metaphor) of the cyborg are bound together.

A clear distinction between subjects and objects is needed to prevent the instrumentalisation of humans. However, this work focuses attention on how a process of alienation from a world where technology is considered an enabling commodity could reinforce the possibility to experience the world through the externalisation of feelings, generating new worlds (Laboria Cuboniks 2015). ${ }^{4}$

\footnotetext{
${ }^{4}$ In 2015 the collective Laboria Cuboniks published 'The Xenofeminist manifesto, a politics for alienation' which presents a new approach to a post-cyber feminism introducing the idea of technoalienation and focus on aspect of technomaterialism, anti-naturalism and gender abolitionism (Hester 2018). As stated in the manifesto 'Xenofeminism seizes alienation as an impetus to generate new worlds' (Laboria Cuboniks 2015).

Contemporary feminism is limited by its predominant investment in local and micropolitical action. However, what xenofeminists think is needed is a feminism capable of systemic intervention. The collective Laboria Cuboniks invest in alienation and the anti-natural, in seizing technology and in embracing the desire for an alien future: 'If nature is unjust, change nature!' (Laboria Cuboniks 2015).The Xenofeminist approach to technomaterialism resonates with the artistic and political framework of $O B$-scene. $O B$-scene embraces the xenofeminist approach and does not argue the primacy of the virtual over the material or vice versa but trys to discuss the new composed
} 
Technologization and industrialization reveal the essentially musical character of things which, however, does not depend on machines but on alienation, on the externalization of feeling. (Perniola 2004: 70)

Borrowing the 'naïve ambition' of Jane Bennett's vital materiality, $O B$-scene aims to free the vitality intrinsic to the matter and not to substitute the human with the technology (Bennett 2010).

\section{THE AUDIENCE, DESIRE THINKING AND SENSORIAL ASSEMBLAGE}

This performance has gone through multiple iterations at exhibitions and conferences. 5

In all iterations, both theoretical and performative, the teasing audio as well as the vaginal probe were both of great interest to the audience. The author has been asked both to publish the teasing audio and to show the probe just after the performance while still wired to her body. The interest of the audience in the unseen sensuous and anatomical aspect of the performance was not unexpected. The idea of disassembly of the performer (the cyborg) has a very deep appeal of messing with the organised system, trying to discern between inorganic and 'disorganic' (Bennett 2010). In Mario Perniola's words 'the sex appeal of the inorganic relies on the generous and hospitable spatiality of the world of things, bodies, sound and thoughts, that infinitely welcome us with unlimited accessibility' (Perniola 2004: 69).

As from Latour's (2009) broken projector, the actant object becomes the subject of an abstract and endless excitation, which Perniola (2004) would call 'neutral sexuality'. On the other hand, the willing dismantling of the cyborg, driven by the desire to denude the cybernetic organism shows the measure in which the erotic relationship between the performer and the audience took place.

For hermeneutic and semiotics aesthetics, it is important to make a clear distinction between subject and object while considering an analysis of a performance (Fischer-Lichte 2008). The necessity to analyse the performance with the aim of give a deeper understanding of the relationship with the audience

\footnotetext{
(Fnote continued)

reality. $O B$-scene focuses on the concept of other/diverse desires, new forms of desiring, experiencing something other (Laboria Cuboniks 2015). In this specific work, this takes the form of a feminism incorporating the fluid, the non-human and the diverse.

${ }^{5}$ The author has been invited to present on this project at Transmediale (Panic Room in the panel 'Post-Digital Anxiety, From C to Xan alphabet of intersectional feminism', Haus der Kulturen, Berlin 2016); FutureFest (FutureLove, Panel 'Synthetic emotions', London 2016); DRHA 2016: Digital Research in the Humanities and Arts (University of Brighton 2016); Metabody Forum (Brunel University 2016), an EU-funded programme involving collaborators and advisors such as Donna Haraway, N. Katherine Hayles, Annie Sprinkle and Ricardo Dal Farra.
}

represents only an attempt which is conducted from the point of view of the performer and supplemented by spontaneous feedback from the audience collected after the performance. This feedback was sometimes surprising: some members of the audience had the desire to share with the author/performer their personal perception of arousal. They were surprised how arousal can be triggered by a performance which contains no explicitly erotic representation. The audience noticed a sense of purity and indirect eroticism, which they found peculiar in an audio-video performance.

$O B$-scene is as an immersive environmental work where the senses, affect and memory were key features of 'assemblage thinking' (Hamilakis 2017).

Hamilakis's exploration of the original thought of Deleuze and Guattari (1986) on assemblages presents the richness and the potential of considering sensorial assemblages as a space for communal experience with political effects, which resonates with the audience perception of $O B$-scene and its design purpose.

In $O B$-scene aesthetics and politics both partake in the constitution of a sensuous framework, which involves contemporary cultural and societal matters of discussion. The concept adopted here is Rancière's definition of politics as a relation between the partition of the sensible for which art must be explained involving and merging together discourse about practices, forms of visibility and patterns of intelligibility (Apter and Rancière 2009). ${ }^{6}$ While the audience's sensuous engagement could be seen as a superficial effect of a scene, the balance between rules that govern what was allowed to be sensed and what was determined as worth perceiving through the senses or recalling mnemonically gave to the performance a profound sense of what Rancière calls 'an "aesthetics" at the core of politics' (2004: 8) by means of the partition of the sensible. This work intentionally focuses on the coexistence between what is given and what is not given and it strives to embrace the members of the audience into a sensorial assemblage that includes aesthetic and political implications.

\section{SENTIC PERFORMANCE AND LANGUAGE OF THINGS}

In previous works of electroacoustic performances, the author focused the attention on the importance of the gesture, trying to program systems to respond to specific gestures with unique sound events (Wessel and Wright 2002), and by using physical interfaces (sound sculptures) equipped with sensors (Troisi, Chiaramonte, Distante, Miranda, Paci Dalo’ and Saldicco 2010).

${ }^{6}$ The author is intentionally adopting the translation 'partition' instead of 'distribution'. The term used by Rancière et al. (2001) was avoir-part (park taking), which is a more apposite term in the context of data, sensors and technology. 
The balance between gesture and acoustic results is of great interest for electroacoustic artistic research and there are several artists who considered the body as a source of music or sound; for example, Atau Tanaka (2006), Federico Visi (Visi, Coorevits, Schramm and Miranda 2017) and others working on the enhancement of the gesture in live performance through wearable instruments. The research on this front is quite technologically advanced and answer to the need of expressivity in electroacoustic performed music.

While in previous works the author sought to hide the technology and minimise the impact of the machines on the performance, in $O B$-scene the reverse is the case. Here the author wanted to experiment with a 'sentic' approach. Emotional response is conceived as input to the machine, which becomes an active and autonomous participant in both the composition and the performance process (Clynes 1995; D’Escriván 2006).

The focus of this article is not on the movements or gestures on music performance but on the interdisciplinary approach which considers a performance as a whole. The performance of the body and the performance of the sound come together without a hierarchy of purpose. In $O B$-scene it is not the gesture producing the sound, or vice versa; instead, sound and body move together in a kind of symbiosis.

The Australian performer Stelarc has used his body as an engineer would use an interface, adapting its surfaces to the artistic purpose. Stelarc experimented with experimental practices introducing the concept of 'obsolete body'. His work 'Amplified Body' (1994), for example, is conceived as a performance/concert where parameters such as EEG Brainwave, Position sensors, Nasal Thermistor, Electrocardiogram (ECG), Electromyography (EMG) and plethysmogram are transformed into sounds (Stelarc 1994).

More recently, Marco Donnarumma, a performer based in Berlin, has addressed the relationship between body, politics and technology, implying the use of mechanomyogram and biofeedback. He combines neuromuscular studies, phenomenology, real-time data analysis, performance practice and music composition (Donnarumma 2017). In Donnarumma's work the body and the way it fuses with the technology is the focus of the performance. This is an interdisciplinary approach where methods borrowed from science, technology, bio-art and sound not only intersect but are combined in order to create novel methods of composition and performance.

This process can be located on a developmental trajectory that starts with the use of electronic musical instruments as an augmentation of existing musical techniques. From there it is a short step to the use of the computer as instrument, and later a technological enhancement of the performer, an organic cyborg performer. The adoption of a cyborg performer is not to be considered an effortless approach, but as a shift of focus from the musical instrument as a tool to the performer as a source of 'things', and more importantly a source of the 'language of things' in the sense of musique concrete methodology and aesthetics (Schaeffer 1946).

The idea of 'the language of things' may seem commonplace for musicians and an audience used to concrete sounds. However, the adoption of data and its aesthetic implications are for many still a step too far from the 'natural' language performed with voice, instruments or objects. In an attempt to enhance 'things' through data, OB-scene adopted the idea of musique concrete as presentations of sonorous objects and not as representations of objects (Cox 2011). This way of looking at the 'ecology of things' is analogous to the 'animist' stage of childhood, an experience of the world populated by animate things rather than passive objects (Bennett 2010).

It can be argued that data represents the medium, and not the mere description of objects through numbers. Consequently, the aesthetic idea of this work is to give continuity to the idea of 'the language of things', in which 'things' are not substituted by data but enhanced by data.

With $O B$-scene the author intends to present a sonorous object in the form of a cybernetic organism; distinct from a representation of a physiological act or phenomenon happening on the scene. It is important to mention that other artists focused their attention on the vagina as a source of data material or sound. Some examples are 'Thrist' by Lauren Lesko, 'Poetica Vaginal' by Joe Davis, 'Vagina Dialogues' by Miya Masaoka and 'Uterine Concert Hal' by Dayna McLeod with different methodologies which are based on an artistic representation of a physiologic intimacy through the use of microphones. OB-scene, by contrast, is centred on the vison of the cyborg as image and concept. The technology is not used to exhibit an intimate physiological nature, it is the body together with the technology that performs, expresses and communicates an intimate emotional state.

\section{MEDIA ARCHAEOLOGY AS METHOD FOR TECHNOLOGY-MEDIATED PERFORMANCE}

The use of the photoplethysmograph, which takes inspiration from the first medical vaginal probes used for diagnostic purposes by Masters and Johnson (1966), introduces a media-archaeological aspect to this work which is worth making more explicit.

There are a few practitioners who have been identified as media-archaeological artists since the 1990s and there are many new artists bringing new ideas in the field taking inspiration from scholarship on mediaarchaeology (e.g., Zielinski, Huhtamo). The use of 
obsolete technology for sound performances has been explored with an explicit contextualisation by Sarah Angliss (Parikka 2013). Other artists such as Cildo Meireles took obsolete technology as their material. Meireles's work 'Babel' (2001) consists of analogue radios of varying ages, from large valve radios dating from the 1920 s to the smaller cheap mass-produced electronic radios of more recent years (Tate 2018). The artist Dani Ploeger in the performance Waste Circuits (2013) used circuit boards from obsolete mobile phones that are melted down on a hot plate and then used to activate the performer's muscles (Ploeger 2013).

Parikka (2013) offers a heuristic tool to attempt to categorise ways in which different artists embraced a media archaeology approach to their work. In his attempt Parikka explores categories of artists who engaged with historical themes, invoked alternative histories offering a critical insight into the new digitality, involved pieces of obsolete technology or engaged with concrete archives.

In developing OB-scene, the author investigated inter-media relations and media-historical borrowings across time. Reinventing new uses for obsolete technology in a non-linear way, as sediment or a layer of media history, served to introduce a more analytical methodology which helped give solidity to the whole performance. It became of interest to analyse if the performance could dig into the question of how and why a certain technology, discourse, or research interest on pleasure and bodies relates to media networks as well as scientific discoveries (Parikka 2013). Adopting Parikka's categories, OB-scene can be grouped with projects where imaginary media are constructed and not just imagined. Many artists have used dead devices or devices that were never built before, reconstructed and re-employed for a renewed artistic purpose.

In the example of the vaginal probe, the author reconstructs a device, which for political/scientific reasons has been considered less interesting to researchers in the field. The understanding of female sexual physiology was of great controversial interest in the 1960s in the United States, but it only focused on dysfunctions later. The interest in understanding pleasure has been considered of minor importance in comparison to the scientific exploration of pain in sexual physiology. Studies on pleasure are now more focused on the psychological aspect while the physiological component has become secondary. It is important to mention that Masters and Johnson focused their research on sexual function and dysfunction with a clear reference to dominant Western belief and values about sexuality. Their sex therapy programme from many perspectives operated as a sort of institution of social control, as sociologists have argued in critiques of Masters and Johnsons' methodology and approach to sex therapy (Morrow 2013). In OB-scene the author intentionally wanted to re-construct a medical probe, which was used by Masters and Johnson to dismantle some preconceptions about sexuality, which they argued led to psychological discomfort and an unsatisfactory sexual life.

The intersection between media archaeology and new materialism has been explored by Parikka (2012), presenting what he calls 'mediatic phenomena' without reducing the theoretical approaches of various form of expressions into a mere discourse about 'media' or 'technology'. Parikka suggests that new materialism is not only about intensities of bodies and their capacities of expression, but is also a more fluid concept. 'Materiality is not just machines - nor is it just solids, and things, or even objects. Materiality leaks in many directions - also concretely' (Parikka 2012: 98). OB-scene aims not only to give voice to matter but also to give fluidity to a theoretical approach to new materialism where bodies, technologies, code and data represent vibrant bits that catalyse into a mediatic event.

\section{Acknowledgements}

Special thanks to Gauti Sigthorsson for his critical reading and knowledgeable insight.

\section{REFERENCES}

Apter, E. and Rancière, J. 2009. Communities of Sense: Rethinking Aesthetics and Politics. Durham, NC: Duke University Press.

Beck, J. G., Sakheim, D. K. and Barlow, D. H. 1983. Operating Characteristics of the Vaginal Photoplethysmograph: Some Implications for Its Use. Archives of Sexual Behavior 12(1): 43-58.

Bennett, J. 2010. Vibrant Matter: A Political Ecology of Things. Durham, NC: Duke University Press.

Biro, M. 2009. The Dada Cyborg. Minneapolis: University of Minnesota Press.

Burland, K. and McLean, A. 2016. Understanding Live Coding Events. International Journal of Performance Arts and Digital Media 12(2): 139-51.

Chivers, M. L., Seto, M. C., Lalumière, M. L., Laan, E. and Grimbos, T. 2010. Agreement of Self-reported and Genital Measures of Sexual Arousal in Men and Women: A Metaanalysis. Archives of Sexual Behavior 39(1), 5-56.

Clynes, M. 1995. Cyborg II: Sentic Space Travel. In C. H. Grey, H. J. Figueroa-Sarriera and S. Mentor (eds.) The Cyborg Handbook. New York: Routledge.

Cox, C. 2011. Beyond Representation and Signification: Toward a Sonic Materialism. Journal of Visual Culture $\mathbf{1 0}$ (2): 145-61.

Deleuze, G. and Guattari, F. 1986. What is an Assemblage? In Kafka: Toward a Minor Literature. Minneapolis: University of Minnesota Press.

D’Escriván, J. 2006. To Sing the Body Electric: Instruments and Effort in the Performance of Electronic Music. Contemporary Music Review 25(1-2): 183-91. 
Donnarumma, M. 2017. On Biophysical Music. In Guide to Unconventional Computing for Music. Cham: Springer.

Fischer-Lichte, E. 2008. The Transformative Power of Performance: A New Aesthetics. Abingdon: Routledge.

Geer, J. H., Morokoff, P. and Greenwood, P. 1974. Sexual Arousal in Women: The Development of a Measurement Device for Vaginal Blood Volume. Archives of Sexual Behavior 3(6): 559-64.

Hamilakis, Y. 2017. Sensorial Assemblages: Affect, Memory and Temporality in Assemblage Thinking. Cambridge Archaeological Journal 27(1): 169-82.

Hayles, N. K. 1999. How We Became Posthuman: Virtual Bodies in Cybernetics, Literature and Informatics. Chicago: University of Chicago.

Heiman, J. R. 1977. A Psychophysiological Exploration of Sexual Arousal Patterns in Females and Males. Psychophysiology 14(3): 266-74.

Heiman, J. R. 1980. Female Sexual Response Patterns: Interactions of Physiological, Affective, and Contextual Cues. Archives of General Psychiatry 37: 1311-6.

Hester, H. 2018. Xenofeminism. Chichester: John Wiley \& Sons.

Laan, E., Everaerd, W., Velde, J. and Geer, J. H., 1995. Determinants of Subjective Experience of Sexual Arousal in Women: Feedback from Genital Arousal and Erotic Stimulus Content. Psychophysiology 32(5): 444-51.

Laboria Cuboniks. 2015. Xenofeminism, a Politics for Alienation, XF Manifesto. www.laboriacuboniks.net/qx8bq. txt (accessed 7 April 2018).

Latour, B. 2009. A Collective of Humans and Nonhumans: Following Daedalus's Labyrinth. In D. Kaplan (ed.) Readings in the Philosophy of Technology. London: Rowman and Littlefield.

Masters, W. H. and Johnson, V. E. 1966. Human Sexual Response. Boston: Little Brown.

Morrow, R. 2013. Sex Research and Sex Therapy: A Sociological Analysis of Masters and Johnson, Vol. 32. Abingdon: Routledge.

Parikka, J. 2012. New Materialism as Media Theory: Medianatures and Dirty Matter. Communication and Criticall Cultural Studies 9(1): 95-100.
Parikka, J. 2013. What is Media Archaeology? Vancouver: John Wiley \& Sons.

Perniola, M. 2004. The Sex Appeal of the Inorganic: Philosophies of Desire in the Modern World. London: A\&C Black.

Ploeger, D. 2013. Waste Circuits. [performance]. Berlin: Transmediale 2014.

Rancière, J. 2004 The Politics of Aesthetics: The Distribution of the Sensible, trans. G. Rockhill. London: Continuum.

Rancière, J., Panagia, D. and Bowlby, R. 2001. Ten Theses on Politics. Theory \& Event, 5(3). https://muse.jhu.edu/ article/32639 (accessed 15 October 2018).

Schaeffer, P. 1946. Notes sur l'expression radiophonique. In Machines à communiquer I: genèse des simulacres. Paris: Seuill.

Stelarc, 1994. Amplified Body. Performance. Rotterdam: V2.

Tanaka, A. 2006. Interaction, Experience and the Future of Music. Consuming Music Together. Netherlands: Springer.

Tate 2018. Cildo Meireles - Display at Tate Modern. www. tate.org.uk/visit/tate-modern/display/media-networks/ cildo-meireles (accessed 7 April 2018).

Tenney, T. 2010. Cybernetics in Art and the Myth of the Cyborg Artist I Tom Tenney. Tomtenney.com. www. tomtenney.com/writing/cybernetics-in-art-and-the-mythof-the-cyborg-artist/ (accessed 15 October 2018).

Troisi, A., Chiaramonte, A., Distante, G., Miranda, E. R., Paci Dalo', R. and Saldicco, C. 2010. Electroshop. Performance. Rome: 46th Nuova Consonanza Festival.

Visi, F., Coorevits, E., Schramm, R. and Miranda, E. R. 2017. Musical Instruments, Body Movement, Space, and Motion Data. Music as an Emergent Multimodal Choreography 13(1). https://jyx.jyu.fi/handle/123456789/54472

Wessel, D. \& Wright, M. 2002. Problems and Prospects for Intimate Musical Control of Computers. Computer Music Journal 26: 11-22.

Wiener, N. 2007. Cybernetics in history (1954). In R. T. Craig and H. L. Muller (eds.) Theorizing in Communication: Readings Across Traditions. London: Sage

Wiener, N. 1988. The Human Use of Human Beings. New York: Da Capo Press.

Zuckerman, M. 1971. Physiological Measures of Sexual Arousal in the Human. Psychological Bulletin 75(5): 297. 